\title{
Author Correction: Molecular basis for the inhibition of the methyl-lysine binding function of 53BP1 by TIRR
}

Jiaxu Wang ${ }^{1}$, Zenglin Yuan (10 2, Yaqi Cui ${ }^{1,3}$, Rong Xie ${ }^{1,3}$, Guang Yang ${ }^{3}$, Muzaffer A. Kassab ${ }^{3}$, Mengxi Wang1, Yinliang $\mathrm{Ma}^{1,3}$, Chen $\mathrm{Wu}^{1}$, Xiaochun $\mathrm{Yu}^{3} \&$ Xiuhua Liu ${ }^{1}$

Correction to: Nature Communications; https://doi.org/10.1038/s41467-018-05174-9; published online 12 July 2018

The original version of this Article contained an error in the author affiliations.

Xiaochun Yu was incorrectly associated with College of Life Sciences, Hebei University, Baoding 071000 Hebei, China.

This has now been corrected in both the PDF and HTML versions of the Article.

Published online: 08 January 2019

\begin{abstract}
(c) (i) Open Access This article is licensed under a Creative Commons Attribution 4.0 International License, which permits use, sharing, adaptation, distribution and reproduction in any medium or format, as long as you give appropriate credit to the original author(s) and the source, provide a link to the Creative Commons license, and indicate if changes were made. The images or other third party material in this article are included in the article's Creative Commons license, unless indicated otherwise in a credit line to the material. If material is not included in the article's Creative Commons license and your intended use is not permitted by statutory regulation or exceeds the permitted use, you will need to obtain permission directly from the copyright holder. To view a copy of this license, visit http://creativecommons.org/licenses/by/4.0/.
\end{abstract}

(C) The Author(s) 2019

${ }^{1}$ College of Life Sciences, Hebei University, Baoding 071000 Hebei, China. ${ }^{2}$ State Key Laboratory of Microbial Technology, Shandong University, Jinan
250100 Shandong, China. ${ }^{3}$ Department of Cancer Genetics and Epigenetics, Beckman Research Institute, City of Hope, 1500 East Duarte Road, 91010
Duarte, CA, USA. Correspondence and requests for materials should be addressed to X.Y. (email: xyu@coh.org) or to X.L. (email: liuxiuhua_2004@163.com) 